\title{
RANCANG BANGUN MESIN KEHADIRAN DENGAN MENGGUNAKAN KODE BAR
}

\author{
Dinar Bhakti W, Agus Trisanto, Ph.D., R. Arum S.P, S.Si, M.T. \\ Jurusan Teknik Elektro-Universitas lampung \\ Jl. Soemantri Brojonegoro No.1 G.Meneng, B. Lampung
}

\begin{abstract}
Abstrak
RANCANG BANGUN MESIN KEHADIRAN DENGAN MENGGUNAKAN KODE BAR. Mesin kehadiran ini menggunakan mikrokontroler ATMEGA 8535 sebagai pengendali mikro, Infra merah dan photodioda sensor untuk mendeteksi kartu dan membaca kode bar yang merepresentasikan nomor pada kartu pegawai, MS. Access sebagai manajemen basis data dan Visual Basic 6.0 untuk antarmuka data ke pengguna. Dari hasil pengujian, Mikrokontroller mampu mengendalikan dari awal sensor masuk hingga ke data base pada computer, masalah yang terjadi yaitu pada pemilihan tegangan PWM untuk memutar motor agar sinkron antara pembacaan dengan kecepatan motor, pemilihan tegangan minimal sebesar $4 \mathrm{~V}$.
\end{abstract}

Kata Kunci: Absensi, karyawan, mikrokontroler, motor, basis data.

\section{PENDAHULUAN}

Seiring dengan itu perkembangan dunia teknologi informasi dan elektronika, semakin dibutuhkannya penggunaan alat pengolah data yang berfungsi untuk mengolah dan menghasilkan informasi yang dibutuhkan. Alat pendukung pengolah data ini dapat berupa sistem absensi untuk karyawan. Hal ini dilakukan untuk memperoleh data kinerja karyawan yang mungkin juga akan berimplikasi pada besar dan kecilnya gaji yang diterima. Oleh karena itu perlu dibuat sebuah Mesin Kehadiran Menggunakan kode bar yang digunakan untuk memudahkan proses absensi dengan menggantikan pola absensi manual yang masih menggunakan kertas. Diharapkan Mesin Kehadiran Menggunakan Kode Bar dapat memberikan kemudahan bagi perusahaan agar dapat mengakses data kehadiran dosen \& karyawan dengan cepat dibandingkan dengan sistem absensi berbasis kertas.

\section{TEORI}

\section{a. Mikrokontroller ATMega8535}

Mikrokontroler ATMega8535 adalah salah satu jenis mikrokontroler keluarga AVR yang diproduksi oleh Atmel Corporation. ATMega8535 merupakan mikrokontroler 8 bit dengan arsitektur RISC (Reduce Instruction Set Computer). Fitur-fitur yang dimiliki oleh mikrokontroler ATMega8535 antara lain:

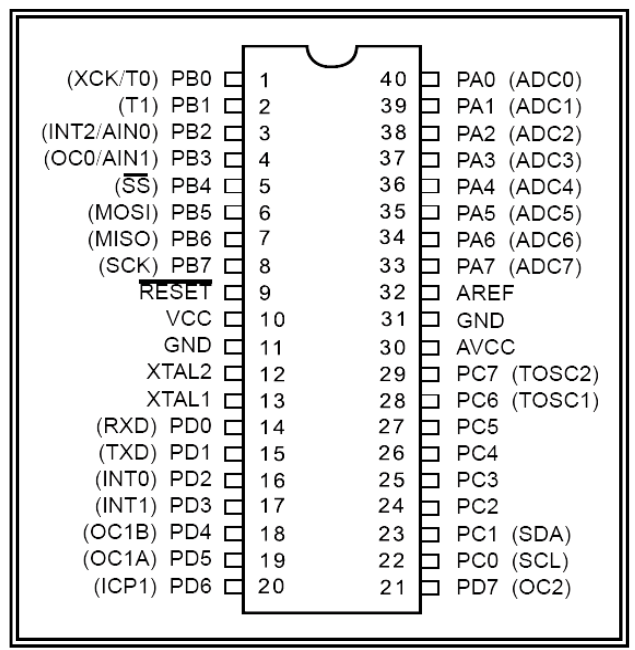

Gambar 1. Konfigurasi Pin Mikrokontroler ATMega8535

a. Lebar data 8 bit.

b. Memiliki 130 buah instruksi.

c. Dapat mencapai kecepatan 16 MIPS (Mega Instruction per Second) pada frekuensi clock 16 $\mathrm{MHz}$.

d. Memiliki $32 \times 8$ register aplikasi umum.

e. $8 \mathrm{k}$ byte flash memory untuk memori program .

f. 512 byte EEPROM untuk memori data nonvolatile.

g. 512 byte SRAM.

h. Dua 8 bit timer/counter.

i. Satu 16 bit timer/counter. 
j. Empat saluran untuk penghasil sinyal $\mathrm{PWM} /$ clock.

k. 8 saluran, 10 bit ADC.

Susunan pin mikrokontroler ATMega8535 tipe DIP (dual in line package) diperlihatkan pada gambar 1.

\section{b. Infra merah \& Photodioda}

Led infra merah adalah jenis dioda yang memancarkan cahaya infra merah. Led infra merah pada dasarnya adalah dioda PN silicon biasa yang dikemas dalam kotak transparan. Led infra merah merupakan salah satu komponen elektronika yang akan mengantar arus jika dialiri bias maju.

Komponen yang dapat menerima infra merah ini merupakan komponen yang peka cahaya yang dapat berupa photodioda. Komponen ini akan mengubah energi cahaya, dalam hal ini energi cahaya infra merah, menjadi pulsa-pulsa sinyal listrik. Komponen ini harus mampu mengumpulkan sinyal infra merah sebanyak mungkin sehingga pulsa-pulsa sinyal listrik yang dihasilkan kualitasnya cukup baik.

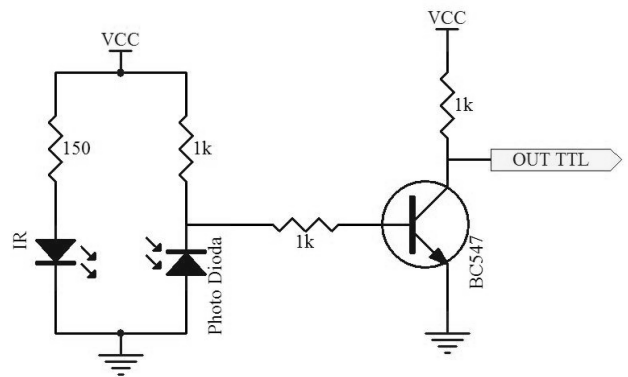

Gambar 2. Photodioda dan Infrared pada pemindai

\section{c. Motor DC}

Motor DC merupakan jenis motor yang menggunakan tegangan searah sebagai sumber tenaganya. Dengan memberikan beda tegangan pada kedua terminal motor DC, motor akan berputar pada satu arah, dan bila polaritas dari tegangan tersebut dibalik maka arah putaran motor akan terbalik pula. Polaritas dari tegangan yang diberikan pada dua terminal menentukan arah putaran motor sedangkan besar dari beda tegangan pada kedua terminal menentukan kecepatan motor.

Motor DC memiliki 2 bagian dasar :

1. Bagian yang tetap/stasioner yang disebut stator. Stator ini menghasilkan medan magnet, baik yang dibangkitkan dari sebuah koil (elektro magnet) ataupun magnet permanen.

2. Bagian yang berputar disebut rotor. Rotor ini berupa sebuah koil dimana arus listrik mengalir.

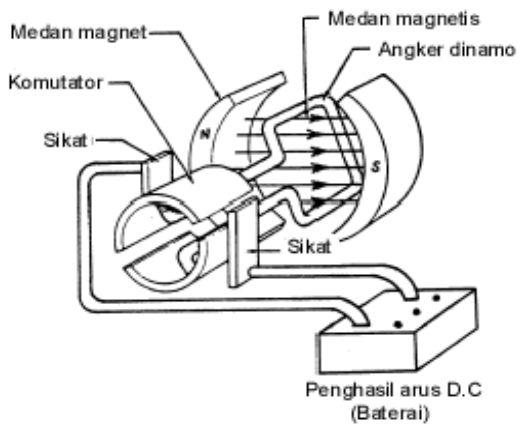

Gambar 3 Motor DC

Gaya elektromagnet pada motor DC timbul saat ada arus yang mengalir pada penghantar yang berada dalam medan magnet. Medan magnet itu sendiri ditimbulkan oleh megnet permanen. Garisgaris gaya magnet mengalir diantara dua kutub magnet dari kutub utara ke kutub selatan. Menurut hukum gaya Lourentz, arus yang mengalir pada penghantar yang terletak dalam medan magnet akan menimbulkan gaya. Gaya F, timbul tergantung pada arah arus I, dan arah medan magnet B.

\section{Pengaturan Kecepatan dengan PWM}

Metode PWM (Pulse Width Modulation) adalah metode yang efektif untuk mengendalikan kecepatan motor DC. Teknik PWM ini bekerja dengan cara mengatur gelombang persegi yang digunakan untuk mensuplay motor DC dengan pulsa High dan Low diatur dengan skala tetentu dari 0 hingga $100 \%$. Gelombang persegi yang digunakan untuk mensuplay motor DC dalam teknik PWM memiliki frekuensi tetap (biasanya max $10 \mathrm{KHz}$ ) namun lebar pulsa high dan low dalam 1 periode yang akan diatur. Perbandingan pulsa high terhadap low ini akan menentukan jumlah daya yang diberikan ke motor DC. Untuk menjalankan motor DC dengan PWM menggunakan rangkaian driver motor DC IC L298.

\section{d. Kode Bar}

Kode bar digambarkan dalam bentuk baris hitam tebal dan tipis yang disusun berderet sejajar horisontal. Untuk membantu pembacaan secara manual dicantumkan juga angka-angka di bawah kode baris tersebut. Angka-angka tersebut tidak mendasari pola kode baris yang tercantum. Ukuran dari kode baris tersebut dapat diperbesar maupun diperkecil dari ukuran nominalnya tanpa tergantung dari mesin yang membaca. Kode bar yang digunakan dalam penelitian ini adalah barcode dengan jenis code 39. Karena pada dasarnya barcode jenis ini memiliki kode yang cukup panjang dalam setiap karakternya dan terdapat banyak 
karakter. Selain itu garis pada barcode yang berjumlah 9 di setiap karakternya akan mempermudahkannya dalam pengubahan kodenya ke dalam bilangan biner dan dalam bentuk ASCII. Satu karakter dalam Code 39 terdiri dari 9 elemen yaitu 5 bar (garis vertikal hitam) dan 4 spasi (garis vertikal putih) yang disusun bergantian antara bar dan spasi. 3 dari 9 elemen tersebut memiliki ketebalan lebih tebal dari yang lainnya oleh karenanya kode ini biasa disebut juga code 3 of 9,3 elemen yang lebih tebal tersebut terdiri dari 2 bar dan 1 spasi. Elemen yang lebar mewakili digit biner 1 dan elemen yang sempit mewakili digit biner 0 .

\section{IIII IIIII IIIII I \\ Gambar 4. Contoh Barcode 39}

\section{PERANCANGAN SISTEM}

Perancangan blok diagram dilakukan dengan tujuan untuk mempermudah realisasi sistem yang akan dibuat. Perancangan blok dimulai dari sebuah sensor transmitter (infra red) dan receiver (Photo diode) yang dipasang pada tempat masuknya kartu. Sensor ini berfungsi untuk mendeteksi adanya kartu yang akan dimasukkan. Saat sensor mendeteksi adanya kartu yang masuk kemudian motor akan diaktifkan untuk menarik kartu.

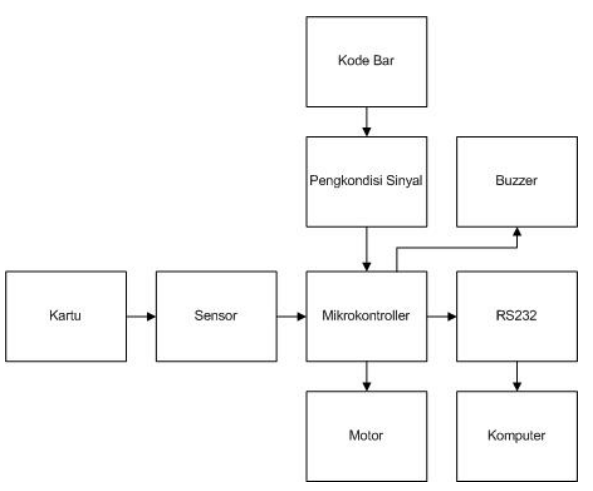

Gambar 5. Blok Diagram

Sensor barcode scanner ini adalah sebuah sensor garis yang digunakan juga sebagai pendeteksi objek dengan permukaan bidang pantul yang kontras yang terdiri atas sebuah infra red dan photodioda. Kartu yang ditarik motor berjalan melewati sensor barcode dikenakan pada barcode-nya. Cahaya inframerah sensor barcode akan mempengaruhi resistansi photodioda dan mengakibatkan tegangan keluaran photodioda menjadi berubah. Pada saat photodioda terkena cahaya, nilai resistansi photodioda semakin kecil sehingga tegangan keluarannya menjadi sangat kecil atau mendekati 0 volt. Sebaliknya saat photodioda tidak terkena cahaya nilai resistansi photodioda menjadi semakin besar sehingga tegangan keluarannya menjadi lebih besar.

Pengaturan arah putaran motor DC dapat diubah secara langsung dengan mengubah polaritas sumber tegangan. Untuk mengubah kecepatan motor DC dapat dilakukan dengan mengubah-ubah besarnya sumber tegangan. Pengontrolan dengan mikrokontroler juga berprinsip seperti tersebut, tetapi dengan sistem yang otomatis. Untuk arah putaran motor DC digunakan driver yang dapat menjalankan motor DC dua arah. Pada mikrokontroller ATmega8535 terdapat saluran PWM yang digunakan untuk mengatur kecepatan dan arah putaran motor DC. Saluran PWM ini adalah gelombang pulsa yang dipakai untuk menjalankan mode switch regulator. Dengan menggunakan PWM kita dapat mengatur kecepatan yang diinginkan dengan mudah. Teknik PWM untuk pengaturan kecepatan motor adalah pengaturan kecepatan motor dengan cara mengubah-ubah besarnya duty cycle pulsa. Besarnya amplitudo dan frekuensi pulsa adalah tetap, sedangkan besarnya duty cycle berubah-ubah sesuai dengan kecepatan yang diinginkan. Semakin besar duty cylce, semakin cepat pula kecepatan motor, dan sebaliknya semakin kecil duty cycle, semakin pelan pula kecepatan motor. Dengan mengontrol duty cycle dari gelombang kotak ini rata-rata tegangan beban dapat dikontrol. Tegangan yang masuk ke motor dihaluskan dengan filter induktor dan kapasitor dengan memberikan ripple yang kecil pada tegangan dc-nya.

Output dari photodioda berupa sinyal analog dikondisikan terlebih dahulu sebelum diumpankan sebagai masukan mikrokontroller melalui pin ADC yang terdapat pada ATmega8535 untuk diubah menjadi bit-bit digital dan selanjutnya dikirimkan melalui IC MAX232 terlebih dahulu sebelum diolah di PC.

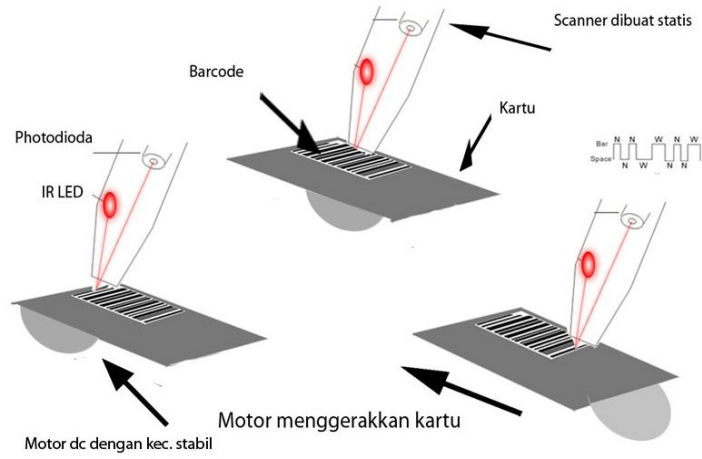

Gambar 6. Skema sistem kerja prototype 
Pada saat konversi ke PC, IC MAX 232 berfungsi sebagai penyearah level tegangan, karena tegangan pada mikrokontroler berkisar antara +5 volt sampai -0 volt sedangkan tegangan pada PC +12 volt dan -12 volt. Konversi terbaca dalam bentuk nomor pegawai, selanjutnya data dikirimkan lewat port serial komputer. Komputer dengan aplikasi yang sudah dibuat akan mencocokkan data yang dimasukkan dengan basis data yang ada di komputer. Jika cocok maka sistem akan menyimpan kehadiran karyawan tersebut dan buzzer akan berbunyi.

\section{a. Skematik Perangkat Keras}

Berikut skematik diagram dari keseluruhan rangkaian yang dibuat. Rangkaian yang dibuat tidak dalam satu PCB, tetapi dibagi menjadi 3 bagian, yaitu PCB Power Supply, Modul Mikrokontroler dan PCB gabungan sensor, komunikasi serial dan driver motor DC.

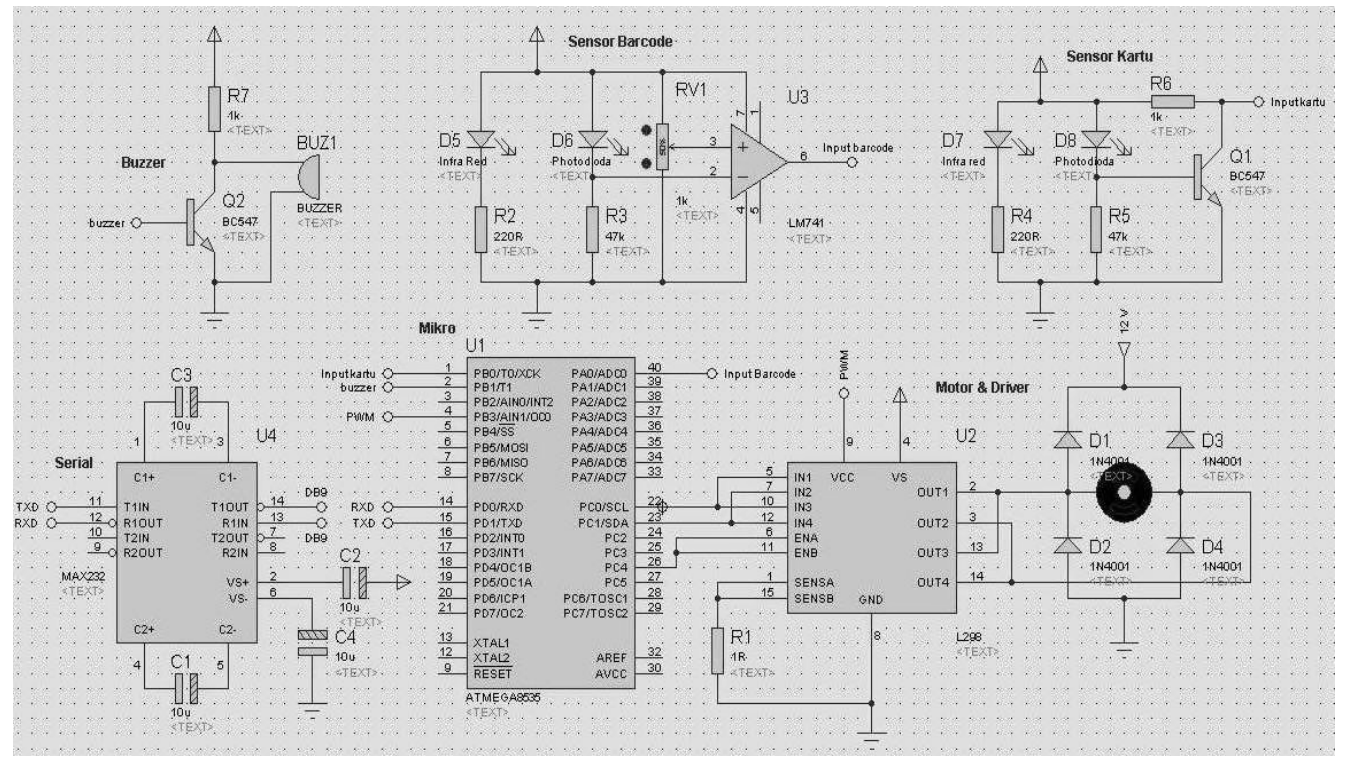

Gambar 7. Skema rangkaian

\section{b. Perangkat Lunak}

Perangkat lunak yang dibuat ialah perangkat lunak antar muka ke sistem untuk kemudahan administrasi dan penyimpanan data. Perangkat lunak untuk alat ini menggunakan program visual basic sebagai antarmuka dan Microsoft Access sebagai manajemen database. Sebelum membuat programnya, perlu dibuat flowchart atau diagram alirnya terlebih dahulu untuk memudahkan dalam membuat program. Diagram alir program ini dibuat sebagai arahan dalam membuat program. Dengan adanya arahan seperti ini, maka akan mempermudah penangkapan logika pemrogramannya.

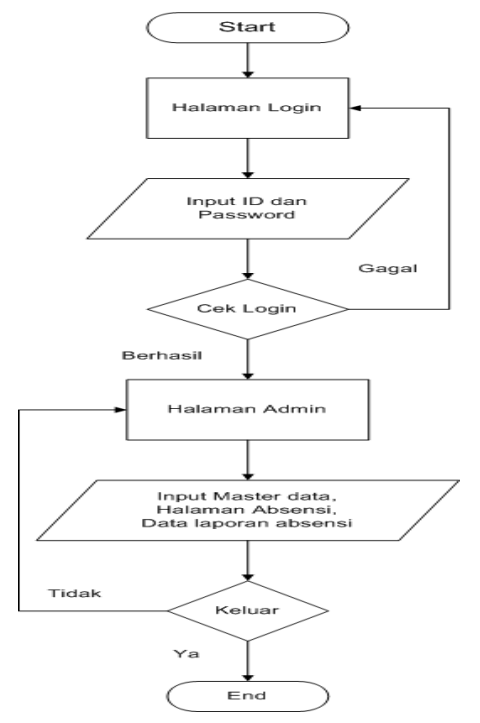

Gambar 8. Diagram Alir 


\section{HASIL DAN PEMBAHASAN}

\section{a. Pengujian hardware}

Rangkaian-rangkaian yang dirancang tersebut kemudian dibuat hardware-nya. Untuk membandingkan antara perancangan awal dan hasil jadi mesin absensi barcode, diperlukan suatu pengujian. Pengujian perangkat keras ini bertujuan untuk mengetahui apakah sistem yang dirancang dapat berjalan dengan baik atau tidak. Adapun perangkat keras yang diuji antara lain:

1. Catu daya

2. Pengendali utama

3. Sensor

4. Komunikasi serial RS232

5. Motor DC

\section{b. Pengujian Software}

Pada pengujian perangkat lunak prosedur pertama admin yang ingin login akan diminta memasukkan password sebagai keamanan dari data dan laporan absensi karyawan. Setelah masuk terdapat beberapa menu seperti master data, absensi, laporan karyawan dan keluar/logout. Menu yang terdapat dalam sistem ini dibagi menjadi 4 bagian yakni :

1. Master Data : Menu untuk memasukkan datadata karyawan dan Nomor Kartunya

Tabel 1 Data Kartu dan Data Kartu yang dibaca oleh sistem

\begin{tabular}{|c|c|c|c|c|}
\hline \multirow{2}{*}{ Percobaan Ke } & \multicolumn{5}{|c|}{ Nomor Kartu } \\
\cline { 2 - 5 } & $\mathbf{1}$ & $\mathbf{7}$ & $\mathbf{1 0}$ & $\mathbf{1 2 5}$ \\
\hline 1 & 1 & 7 & 10 & - \\
\hline 2 & 1 & 7 & 10 & 125 \\
\hline 3 & - & - & - & - \\
\hline 4 & - & - & - & - \\
\hline 5 & 1 & 7 & 10 & - \\
\hline 6 & 1 & - & 10 & 125 \\
\hline 7 & 1 & 7 & & - \\
\hline
\end{tabular}

2. Absensi $=$ Menu ini untuk menampung data absensi karyawan yang meliputi Jam Masuk, Jam Keluar Istirahat, Jam Masuk Istirahat dan Jam Pulang.

3. Report $=$ Menu ini digunakan untuk melihat dan mencetak laporan absensi, per hari atau per bulan.

4. Keluar $=$ Menu untuk keluar dari sistem.

\section{c. Pengujian Keseluruhan}

Setelah melakukan penelitian seperti di atas maka dilakukan pengujian sistem dengan mengintegrasikan dari masing-masing subsistem untuk melihat sejauh mana prototype bekerja dengan baik. Dari tabel di atas digunakan 4 buah sampel kartu dan setiap kartu dilakukan percobaan sebanyak 7 kali. Setelah melakukan pengujian didapatkan kesalahan pembacaan kartu pada beberapa kali percobaan, contohnya kartu dengan nomor 1 sempat tidak terbaca dengan benar dan kartu bernomor 7 terbaca dengan benar sebanyak 3 kali Kemudian dilakukan percobaan dengan penambahan digit barcode hingga 2-3 digit yaitu pada nomor kartu 10 dan 125 juga terdapat kesalahan.

Data kartu yang dimasukkan dan data kartu yang berhasil dibaca dan disimpan absennya oleh sistem disajikan oleh tabel 1 sebagai berikut : 


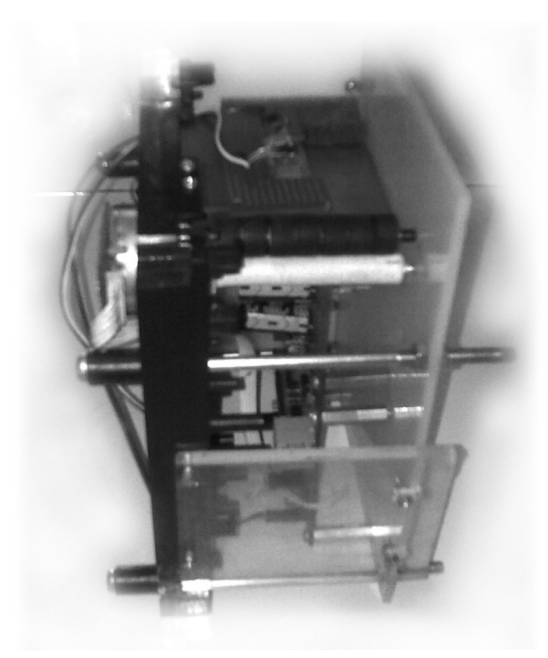

Gambar 9. rancangan pembaca barcode

Dari kesalahan tersebut tidak berupa kesalahan pembacaan nomor melainkan tidak tampilnya nomor dari kartu yang dipindai. Semua sampel barcode mempunyai garis tebal berukuran $2 \mathrm{~mm}$ dan garis tipis berukuran $1 \mathrm{~mm}$ atau $2: 1$. Setelah diamati kesalahan yang terjadi dikarenakan beberapa faktor yaitu :

a. Desain sensor dan fokus yang masih kurang presisi, mengakibatkan cahaya LED infra merah kurang tepat mengenai photodioda.

b. Tingkat kepekatan warna hitam pada garis barcode, mengakibatkan kekuatan cahaya dari LED infra merah berkurang sehingga tidak terdeteksi oleh photodioda.

c. Kartu tidak dimasukkan secara sempurna pada posisinya, mengakibatkan garis barcode pada kartu miring/tidak berada tegak lurus dengan posisi sensor.

d. Kecepatan dari motor yang berubah-ubah dan kurang stabil mengakibatkan pembacaan yang kurang benar dan tidak presisi.

e. Besarnya tegangan PWM yang di-supply ke motor tidak boleh melebih $5 \mathrm{~V}$ karena dapat menyebabkan motor berputar melebihi kecepatan pembacaan sensor sehingga sensor tidak dapat membaca kartu yang melewatinya, juga tidak boleh kurang 3,6 V karena motor tidak mempunyai kekuatan untuk memutar torsi motor. Tegangan yang digunakan untuk memutar untuk memutar motor minimal $4 \mathrm{~V}$ agar motor dapat berputar stabil dengan kecepatan pembacaan pemindai.

\section{KESIMPULAN}

Dari pembahasan dan analisis dapat disimpulkan bahwa :

1. Mesin Absensi Karyawan berhasil dirancang dengan menggunakan mikrokontroller ATMega 8535 dengan bahasa pemrograman $C$, dan perancangan antarmuka perangkat lunak menggunakan bahasa pemrograman Visual Basic 6.0.

2. Setelah melakukan pengujian, mesin absensi ini dapat memasukkan data karyawan yang melakukan absensi dan perangkat lunak menyesuaikan dengan data karyawan sesuai dengan data yang ada di master data. Data absensi yang direkam meliputi jam masuk, jam keluar istirahat, jam masuk istrirahat dan jam pulang.

3. Perangkat ini bekerja sebagai pengganti sistem absensi berbasis kertas. Dengan begitu dapat dilakukan absensi dengan lebih mudah, lebih akurat dan lebih cepat dalam dalam proses absensi dan pelaporan. Sistem manual bisa difungsikan sebagai back up / cadangan jika sitem baru gagal / error.

4. Setelah melakukan pengujian, dari 7 kali percobaan mesin ini memiliki persentase keakuratan pembacaan sebesar $30 \%$ dengan nomor kartu jumlah digit yang berbeda-beda.

\section{DAFTAR PUSTAKA}

1. Firdaus. 2006. 7 Jam Belajar Interaktif Visual Basic 6.0 untuk Orang Awam. Palembang: Maxikom.

2. Heryanto, M. Ary and Adi P, Wisnu. 2008. Pemrograman Bahasa C untuk Mikrokontroler ATMEGA8535. Yogyakarta: Penerbit Andi.

3. Malvino, Albert Paul. 2003. Prinsip-prinsip Elektronik. Jakarta: Salemba teknika

4. Schuler. 1996. Electronics Principles and Applications. New York : Mc Graw Hill

5. Winoto, Ardi. 2008. Mikrokontroler AVR ATmega8/32/16/8535 dan Pemrogramannya dengan Bahasa $C$ pada WinAVR. Bandung: Penerbit Informatika. 